\title{
A gestão acadêmica da pós-graduação lato sensu: o papel do coordenador para a qualidade dos cursos
}

Marília Fonseca'

Dirce Mendes da Fonseca'

\section{Resumo}

0 texto tem com o foco de análise o papel e a concepção dos cursos de pós-graduação lato sensu a partir de sua contextualização e dos marcos regulatórios. Destaca a função acadêmica atribuída às instituições de ensino e aos gestores, com vistas a refletir sobre as funções políticas, administrativas e pedagógicas de coordenadores de cursos de pós-graduação, com especial destaque para os cursos lato sensu. 0 referencial metodológico utilizado tomou como base os pareceres, as resoluções e portarias emitidas pelo Ministério da Educação (MEC) e pelo Conselho Nacional de Educação (CNE), a partir dos anos 1960. Examinou, ainda, a literatura voltada para a análise crítica sobre a normatização dos cursos. 0 artigo reflete sobre a contração do financiamento da educação superior na década de 1990, o que facilitou o aumento expressivo de instituições privadas e, particularmente, a proliferação de cursos lato sensu, entre eles, os cursos corporativos oferecidos por instituições públicas. Essa ocorrência, somada à inexistência de regulamentação para a oferta, traz riscos para a qualidade desses cursos. 0 texto evoca as responsabilidades de coordenadores e gestores de cursos pela garantia da qualidade dos cursos, intensificando a interlocução entre teoria e prática, a articulação entre conteúdos e o mundo do trabalho, e, essencialmente, a dimensão formativa do aluno, que supõe prepará-lo para o exercício da ética e da cidadania em quaisquer das dimensões sociais em que venha a inserir-se no futuro.

\section{Palavras-chave}

Gestão pedagógica de cursos - Regulação da pós-graduação lato sensu - Função do coordenador de cursos.

I- Universidade de Brasília, Brasília, DF, Brasil.

Contatos: mariliasfonseca@gmail.com;

mendesdirce@yahoo.com.br 


\title{
The academic management of lato sensu graduate education: The role of the coordinator for the quality of the courses
}

\author{
Marília Fonsecal \\ Dirce Mendes da Fonsecal
}

\begin{abstract}
This article analyzes the role and concept of lato sensu graduate courses, looking at them in context, and according to regulatory frameworks. It highlights the academic role assigned to educational institutions and managers, reflecting carefully on political, administrative and educational roles of the coordinators of graduate courses, with special attention to lato sensu courses. Its methodology has used the recommendations, normative resolutions and decrees issued by the Ministry of Education (MEC) and the National Council of Education, since the 1960s. It also examines literature on the critical analysis of course normative standards, and reflects on the reduced funding of higher education in the 1990s, which has led to a significant increase in private institutions, and especially to the increase in lato sensu courses, including corporate courses offered by public institutions. This and the lack of regulation of course offers bring risks to the quality of those courses. Course coordinators and managers are responsible for guaranteeing course quality by encouraging the interlocution between theory and practice, the articulation between content and the world of work, and mainly the formative dimension of students, who should be educated to exercise ethics and citizenship in any social dimension they might be involved with in the future.
\end{abstract}

\section{Keywords}

Course educational management - Regulation of lato sensu graduate courses - Course coordinator role.

I- Universidade de Brasília, Brasília, DF, Brasil.

Contacts: mariliasfonseca@gmail.com;

mendesdirce@yahoo.com.br 


\section{Introdução}

A partir da década de 1990, houve acelerado aumento dos cursos de especialização nas modalidades stricto e lato sensu. Diante da nova conjuntura do mercado de trabalho com forte influência do processo de globalização e da permanente necessidade de capacitação técnico-profissional dele decorrente, as instituições de ensino públicas e privadas passaram a desenvolver atividades de capacitação em todas as áreas do conhecimento, utilizando-se largamente dos cursos de pós-graduação lato sensu. Esse processo foi facilitado a partir de 1995 pela decisão do governo vigente de dar flexibilidade às normas para criação de cursos e instituições de nível superior (centros universitários ou instituições isoladas).

Tal orientação foi apoiada pelo então Ministro da Educação, Paulo Renato de Souza, o que abriu caminho para o aumento significativo de instituições privadas. Ao se referir à política de avaliação e expansão do ensino superior, o ministro argumentava que as limitações orçamentárias impediam a ampliação e diversificação da esfera pública, o que gerou dependência da oferta da iniciativa privada (SOUZA, 1999).

Os diferentes níveis e modalidades de cursos de pós-graduação - lato sensu, stricto sensu e mestrado acadêmico ou profissional têm objetivos e características diferentes, que exigem múltiplas atividades do coordenador de curso. Uma delas é, sem duvida, comum a todos os coordenadores: a função tridimensional de coordenador, professor-pesquisador e gestor. Essa atuação complexa relaciona a docência com a pesquisa, formando com esta um amálgama que promove a produção de conhecimentos em lugar de sua mera reprodução.

Por se tratar de modalidade que perdura ao longo da vida, os cursos de especialização stricto e lato sensu não se restringem à dimensão pragmática de preparação direta para o trabalho ou para ascensão na carreira, como vem sendo costumeiramente compreendido pelo senso comum. A dimensão formativa do educando é requisito fundamental para a qualidade dos cursos, na medida em que prepara o indivíduo para o exercício da cidadania, que transcende o limite do campo profissional.

A oferta dos cursos requer, pois, por parte da instituição que os oferece, observar o rigor acadêmico, como forma de preservar a sua qualidade. Um dos requisitos mais importantes é a gestão dos cursos e, no contexto do presente artigo, ressalta-se mais especificamente a função do coordenador. No entanto, a partir do final dos anos 1990, esses cursos, embora conferissem certificação de especialização, foram sendo negligenciados pela normatização e pelo processo de avaliação da Coordenação de Aperfeiçoamento de Pessoal de Nível Superior (Capes).

Os estudos empíricos e ensaios críticos sobre o tema evidenciam o peso da gestão institucional para a qualidade dos cursos lato sensu. Em seu estudo de mestrado, Silva (2008) analisou a experiência de duas universidades do Distrito Federal no período de 2003 a 2006 (uma pública e outra privada/confessional). Ambas ofereceram cursos de formação e aperfeiçoamento, levando em conta o interesse dos profissionais, das empresas e das instituições. Embora o objetivo central dos cursos fosse voltado para o trabalho, foram desenvolvidos elementos de valorização da ética, tanto no plano da formação quanto no plano do exercício profissional. Fica patente, pois, que os gestores de cursos lato sensu contam com graus de liberdade para fazer escolhas no sentido de suplantar a limitação pragmática de cursos profissionalizantes.

Costa (2010) analisou cursos de pós-graduação lato sensu oferecidos pelo Centro de Formação, Treinamento e Aperfeiçoamento da Câmara dos Deputados. 0 estudo identificou fatores de relevância acadêmica, tais como a organização de grupos de pesquisa articulados aos cursos, forte apoio à gestão e preparo do corpo docente. Um dos fatores positivos foi o processo de acompanhamento dos egressos, que apontou elementos para o contínuo aperfeiçoamento dos cursos.

As experiências relatadas indicam que a forma como a gestão institucional organiza pedagógica e administrativamente os cursos faz a diferença quanto à sua qualidade. No campo especí- 
fico do presente estudo, a função do coordenador é o principal foco de análise. Parte-se do ponto de vista de que o ato de coordenar implica atividades múltiplas e, portanto, é necessário ter clareza quanto às finalidades que residem no campo da política educacional do país e dos objetivos definidos pelas instituições em seu campo específico. 0 coordenador acadêmico é um ator central para a qualidade do curso no que toca à interlocução entre teoria e prática e à articulação entre os conteúdos disciplinares e o mundo do trabalho. Acima de tudo, cabe a ele garantir a dimensão formativa do educando. Esse requisito remete diretamente à dimensão do direito individual ao conhecimento para compreender e ter acesso a todas as manifestações da cultura humana e, ainda, para preparar o indivíduo para o exercício da ética e da cidadania em quaisquer das dimensões sociais em que venha a inserir-se no futuro.

0 presente texto tem como finalidade acrescentar algumas reflexões à literatura conexa, partindo do pressuposto de que os cursos lato sensu oferecem relevantes contribuições para a educação continuada, o que pode ser evidenciado pela crescente procura por vagas.

\section{A gestão de cursos de pós-graduação: entre o pragmatismo} e a relevância social

0 processo de produção e consumo do conhecimento tem ocupado lugar de destaque nos debates do campo epistemológico. 0 estudo de Oliveira e Fonseca (2005) trata das diferentes proposições atinentes ao papel do conhecimento na dinâmica social, que tiveram lugar a partir do final do século XX. Entre essas, destaca-se a vertente pragmática, que confere lugar de destaque ao conhecimento técnico-científico para a inserção dos indivíduos no mercado de trabalho e para a competição econômica entre nações. Referindo-se a Harvey (1992), o estudo mostra que, embora o conhecimento tivesse sempre importância na luta competitiva, a partir da dinâmica econômica conhecida como globalização, passou por um processo de produção organizada do saber, que vem adquirindo cada vez mais um valor comercial. Esse fato, aliado ao desenvolvimento das novas tecnologias da informação, alimenta a concorrência entre os diferentes países e segmentos produtivos e também as tendências, observáveis nos países mais desenvolvidos, de conectar as instituições de educação superior a indústrias de alta tecnologia. Essa é, sem dúvida, uma forma simbiótica de produção de conhecimentos tecnológicos, capaz de garantir a atualização contínua do saber para a competitividade no mercado global.

Outra vertente leva em conta o papel do conhecimento em meio às diferentes configurações da coletividade humana, fazendo valer a autonomia dos sujeitos. Nessa acepção, o ato educativo aproxima-se da proposta de autorreflexão crítica de Adorno (1995). 0 autor sustenta que a educação profissional transcende o limite da instrumentalização para a adaptação ao mundo competitivo. Como este privilegia os mais poderosos e mais aptos, a proposta de Adorno é preparar o indivíduo para a prática da autonomia, no sentido de fazê-lo senhor de seu próprio entendimento sobre o mundo e, portanto, senhor de si mesmo no âmago do mercado competitivo.

A tendência pragmática inerente ao processo de globalização repercutiu na Reforma do Aparelho do Estado (BRASIL/MARE, 1995). A administração pública adotou um modelo gerencial com o objetivo de imprimir eficiência ao desempenho do Estado, tornando-o mais compativel com a atual fase do capitalismo competitivo. A educação foi um dos setores diretamente atingidos pela reforma. 0 financiamento da educação superior pública sofreu uma contração significativa, o que gerou oportunidade para o aumento expressivo de instituições privadas. 0 estudo de Moraes (2010) argumenta que esse fato, aliado à política de redução do financiamento estatal, incitou a proliferação de cursos lato sensu, geradores de receitas adicionais, tanto nas instituições privadas como na esfera pública. Essa circunstância contribuiu para que a oferta de cursos por instituições privadas suprisse as demandas imediatas do mercado. Ressalte-se ainda que grande parte dos cursos de especialização oferecidos por universidades públicas 
é paga. Isso gerou um viés privatizante nessas instituições, ferindo o princípio da gratuidade do ensino superior público.

Alguns cursos passaram a ser oferecidos na modalidade corporativa. Dentre eles, inscrevem-se os mestrados de cunho profissionalizante (stricto sensu) para o ramo de executivos e de negócios (MBAs). No setor público, existem as chamadas escolas de governo, entre elas: o Instituto Legislativo Brasileiro (ILB), criado em 1997 como um centro de estudos dedicado a qualificar os servidores do Senado Federal para o exercício de suas funções; a Universidade do Legislativo Brasileiro (UNILEGIS), criada pelo Senado em 2001, com o objetivo de contribuir com o processo de integração e modernização dos parlamentos brasileiros, nas esferas federal, estadual e municipal. 0 Instituto Superior do Ministério Público, localizado no Rio de Janeiro, é uma entidade civil sem fins lucrativos, mantida pela Associação do Ministério Público do Estado do Rio de Janeiro (AMPERJ). Tem por objetivo a realização de atividades visando a desenvolver e incentivar estudos, pesquisas e trabalhos sobre os aspectos institucionais, funcionais e culturais da atuação do Ministério Público (MP). Seu carro-chefe é a oferta de cursos de extensão, aperfeiçoamento e pós-graduação certificados pelo Ministério da Educação (MEC) ${ }^{1 .}$

A Escola Nacional de Administração Pública (ENAP) é uma instituição do poder executivo que oferece formação e aperfeiçoamento em administração pública para servidores públicos federais. Vinculada ao Ministério do Planejamento, Orçamento e Gestão, foi criada em 1986 (BRASIL/MPOG, 2002). Nos anos 1990, dedicou-se a formar quadros técnicos para o serviço público, em atendimento às demandas da reforma administrativa então em curso, sob a coordenação do ministro Bresser Pereira (BRASIL/MARE, 1995). A intenção declarada, segundo Nunes (1998, p. 20), era "aproximar a forma de gestão das instituições públicas (referidas como agências executivas) à

1- As informações sobre os cursos oferecidos pelo Senado federal encontramse no site <www.12.senadoilb/br/>. Acesso em agosto de 2014. Ver também: $<$ http://www.amperj.org.br/ismp/>. Acesso em setembro de 2014. forma de gestão das instituições privadas competitivas". Ante tal perspectiva, o conhecimento disseminado por meio dos seus cursos não poderia servir a outro objetivo que não fosse o da capacitação em serviço, delimitada por marcos ideológicos da Reforma do Estado. Tendo como princípio a eficiência dos funcionários em sua atuação profissional, a gestão de instituições públicas passou a ter importância fundamental como um dos elementos para alcançar os parâmetros de qualidade do serviço público requeridos pela reforma, sob o desígnio da eficiência e da competitividade 2 .

Outros parâmetros de qualidade dos cursos de pós-graduação, em todas as suas modalidades, foram estabelecidos nos marcos regulatórios do Plano Nacional de Pós-Graduação - PNPG 2005-2010 (BRASIL/MEC/CAPES, 2005). Como um de seus objetivos fundamentais, o Plano dispõe que os cursos de especialização façam parte do sistema de pós-graduação. Pretende também que esse sistema seja expandido, com a devida capacitação do corpo docente, tanto para os cursos stricto sensu quanto para os de lato sensu, compreendendo a especialização de profissionais para o mercado de trabalho público e privado (incluindo-se aqui a capacitação de professores para os níveis básico e superior de ensino), além da formação de técnicos e pesquisadores para empresas públicas e privadas.

Não há dúvida de que tais esforços para o aperfeiçoamento da pós-graduação tenham respondido prioritariamente aos apelos dos mercados profissionais onde o conhecimento tem importância ímpar no sentido de preparar o indivíduo para a nova conformação do campo

\footnotetext{
2- Tais instituições fazem parte de rede nacional composta de 203 instituições governamentais, com diferentes trajetórias e formatos, da qual participam: escolas de governo propriamente ditas, centros de treinamento e capacitação, universidades corporativas, secretarias de administração de estados e de municípios, entre outras. Algumas dessas instituições foram criadas em meados do século passado, mas a grande maioria possui histórico de constituição mais recente, surgindo após o processo de redemocratização do país e a edição da Constituição Federal de 1988. As instituições estão assim distribuídas: 61 de nível federal (30\%), 94 de nível estadual (46\%) e 48 de nível municipal (24\%). Cerca de $70 \%$ são vinculadas ao Poder Executivo, enquanto que as demais aparecem distribuídas entre os Poderes Legislativo e Judiciário, além do Ministério Público. A relação das instituições participantes pode ser acessada em: <http://www2.enap. gov.br/rede_escolas/>.
} 
do trabalho. No entanto, os cursos de pós-graduação lato sensu não receberam o mesmo cuidado por parte da política educacional e do já citado Plano Nacional de Pós-Graduação 2005-2010 (BRASIL/MEC/CAPES, 2010). Prova é que, nos planos subsequentes, os mesmos foram contemplados no campo regulatório e avaliativo da Capes.

O Plano Nacional de Pós-Graduação 20112020 também se limita a regulamentar os cursos stricto sensu. É evidente que essa modalidade tem uma função fundamental no desenvolvimento técnico-profissional e a Capes, como agência de fomento, tem exercido um papel relevante para resguardar a qualidade dos cursos. Não se pretende aqui comparar o lato sensu com o stricto sensu, visto que são dimensões diferenciadas. 0 objetivo é chamar a atenção para a necessidade de requalificar esse nível de ensino, que historicamente tem dado relevante contribuição à qualificação técnico-profissional dos indivíduos que ingressam nos setores público e privado. A requalifıcação implica redefinir a concepção dos cursos e a forma de supervisão dos órgãos competentes responsáveis pelo credenciamento e avaliação das instituições de ensino. Em especial, é preciso estabelecer quais instituições possuem condições acadêmicas para ofertá-los, notadamente a partir da avaliação do corpo docente.

\section{A pós-graduação lato sensu no contexto do marco regulatório brasileiro: 1951-2014}

Os cursos de especialização tiveram um papel importante na formação de professores de nível superior. A criação, pela Capes, do Decreto $n^{\circ}$ 29.741/1951 tinha por objetivo "assegurar a existência de pessoal especializado e quantidade e qualidade suficientes para atender as necessidades dos empreendimentos públicos e privados que visam ao desenvolvimento do país" (BRASIL, 1951). Uma das iniciativas mais importantes foi a contratação de professores visitantes estrangeiros, que tinham como uma de suas funções a realização de atividades em cursos de aperfeiçoamento e de especialização para capacitar profes- sores brasileiros. Nesse período, os cursos de pós-graduação foram regulamentados pelo Parecer $n^{\circ}$ 977/1965 da Capes, que os qualificou como pós-graduação stricto e lato sensu. A partir de então, estes últimos passaram a ser regulamentados pela Resolução no 12 do Ministério da Educação (MEC) / Conselho Nacional de Educação (CNE), de dezembro de 1983. A Resolução focalizava a formação didático-pedagógica, considerando que a maioria desses cursos destinava-se à formação e atualização de professores do ensino superior. Exigia-se pelo menos $85 \%$ de presença e nota 7 (sete) de desempenho acadêmico. A pós-graduação lato sensu esteve sob a supervisão da Capes até 1991, quando lhe foi atribuída a elaboração do Plano Nacional de Pós-Graduação (PNPG).

À medida que se consolidavam os cursos de mestrado e doutorado, a pós-graduação lato sensu foi perdendo espaço no quesito formação de professores, e paulatinamente a oferta e os critérios de qualidade tornaram-se mais flexíveis. Prova é que a atual Lei de Diretrizes e Bases da Educação Nacional (LDB, Lei ${ }^{\circ}$ 9.394/1996, art. 66) determina que os cursos de formação para o exercício do magistério superior sejam preferencialmente ofertados pelos programas de mestrado e doutorado.

Apesar dessa contratura no campo legislativo, os cursos lato sensu continuaram a ocupar espaço importante, considerando a sua crescente oferta em instituições públicas e principalmente privadas. 0 Conselho Nacional de Educação, pela Resolução Câmara da Educação Superior/CNE de 3 de outubro de 1999, determinou que tais cursos ficassem sujeitos à avaliação da Capes. No entanto, esses cursos, embora conferissem certificação de especialização, foram sendo negligenciados pela normatização e pelo processo de avaliação da Capes, que diminuiu inclusive a exigência de qualificação do corpo docente para atuar em tais cursos. Segundo a citada Resolução, podem lecionar profissionais de alta competência e experiência em áreas específicas do curso, desde que aprovados pelo Conselho de Ensino e Pesquisa, no caso das universidades e centros universitários, ou pelo colegiado equivalente, no caso das demais instituições de ensino superior. 
Posteriormente, a Resolução $\mathrm{n}^{\circ} 1$ CNE/ CES (2001) não mencionou a Capes como órgão responsável pela avaliação da especialização. Revela-se um paradoxo o fato de que, na medida em que o país se fortalece na qualificação de mestres e de doutores, o nível de exigência de qualificação para lecionar nos cursos de pós-graduação lato sensu fica mais flexível. Tal fato pode ser explicado, em parte, pela pressão e expansão do campo privado, que guarda a maior oferta desses cursos, e que tem um número menor de professores com titulação de mestres e doutores. Não obstante, a Resolução dispõe que o corpo docente da pós-graduação deverá ser constituído de, pelo menos, 50\% de professores com a titulação de mestre ou de doutor. Sobre essa questão, Pilatti (2006) adverte sobre as distorções na oferta desses cursos. 0 que chama a atenção na fala a seguir é o fato de que algumas instituições se utilizam de entidades intermediárias não qualifıcadas para ministrarem cursos de especialização, presenciais ou a distância. Segundo o autor, esse fato sinalizava uma forma de terceirização na oferta de cursos:

A flexibilidade das normas vigentes, permitindo que instituições credenciadas ofereçam especializações fora do seu município sede ou de sua unidade federada, segundo alguns, tem levado a algumas distorções. Com frequência, estudantes e instituições questionam o fato de instituições utilizarem entidades intermediárias não qualificadas para viabilizarem a oferta de cursos de especializações presenciais ou a distância. Alguns Conselhos Estaduais de Educação ou mesmo organizações diversas, órgãos públicos e empresas também têm manifestado preocupação quanto à validade de cursos de especialização de qualidade questionável oferecidos daquela forma. (PILATTI, 2006, p. 22).

Em consequência da flexibilidade da legislação reguladora ao longo dos anos, várias informações negativas chegaram ao Ministério da Educação. Assim, motivado por denúncias pontuais que revelavam irregularidades na oferta desses cursos, o ministro da Educação instituiu, em 2004, uma Comissão Especial de Acompanhamento e Verificação, integrada pela Secretaria de Educação Superior (SESU) e o Instituto Nacional de Estudos e Pesquisas Educacionais Anísio Teixeira (INEP), para acompanhar e verificar a exatidão do cumprimento das disposições da Resolução CES/ CNE $n^{\circ} 1$, de 2001, referente aos cursos de pós-graduação lato sensu oferecidos por instituições de ensino superior ou por instituições especialmente credenciadas para atuar nesse nível educacional, na modalidade presencial e a distância, bem como oferecer sugestões de procedimentos que possibilitassem o aprimoramento das ações de supervisão desses cursos.

A Comissão detinha poderes para fiscalizar a abertura de cursos e o funcionamento dos mesmos. Por meio da Portaria $\mathrm{n}^{\circ} 1.180$, de 6 de maio de 2004, o ministro da Educação alertava:

Vamos dar um basta à desregulação que permitiu a proliferação de cursos de pósgraduação sem qualidade em todo o país. Com ações como esta, queremos aprimorar a qualidade da educação no Brasil. Por isso, não podemos aceitar anarquia no ensino da pós-graduação no Brasil. (BRASIL, 2004, p. 9).

Como consequência da portaria do ministro, a Comissão elaborou um roteiro de projeto pedagógico, contendo os seguintes elementos referenciais: nome do curso e área de conhecimento; histórico da instituição; objetivos do curso; público-alvo; concepção do programa; coordenação; carga horária; período e periodicidade; conteúdo programático; corpo docente; metodologia; interdisciplinaridade; atividades complementares; tecnologia; infraestrutura física; critérios de seleção; sistema de avaliação; controle de frequência; trabalho de conclusão; indicadores de desempenho; certificação; relatório circunstanciado e roteiro do projeto pedagógico.

Em 2005, como resultado das citadas deliberações, todos os cursos de pós-graduação lato sensu foram registrados no MEC. De acordo com os dados do Censo da Educação Superior 
(BRASIL/MEC, 2009; 2012), 127 instituições públicas e 716 instituições privadas ofereciam esses cursos. Em 2012, pelos dados do mesmo Censo, o setor público já contava com 304 instituições e o setor privado, com 2.112 para a oferta dos cursos. A partir daí, a Comissão foi extinta, sendo que nem a SESU nem o INEP deram continuidade ao acompanhamento dos cursos. Como consequência, o Censo da Educação não disponibilizou novos dados sobre o número de cursos de pós-graduação lato sensu e nem sobre os alunos formados. Essa ausência de informações constitui uma lacuna significativa no sistema de avaliação e de acompanhamento dos cursos por parte do Ministério da Educação e do Conselho Nacional de Educação.

Em 2007, a Resolução n ${ }^{\circ} 1$ do CES/CNE (2007) apresentou algumas alterações para o funcionamento de cursos de pós-graduação. Entre elas, excluiu os cursos de aperfeiçoamento da categoria de cursos de pós-graduação. A qualificação do corpo docente dos cursos de especialização foi definida no inciso IV, e ficou mais flexível ainda:

[...] o corpo docente de cursos de pós-graduação lato sensu em nível de capacidade técnico-profissional, sendo que cinquenta por cento destes, pelo menos, deverão apresentar titulação de mestre ou de doutor, obtida em programas de pósgraduação stricto sensu, reconhecidos pelo Ministério da Educação.

Fica evidente que a Resolução deixa uma lacuna referente à metade do corpo docente, deixando a critério das instituições e, em especial, do coordenador do curso definir a titulação, o que permite inclusive que haja professores apenas com graduação lecionando em cursos de pós-graduação lato sensu, sem ferir a Resolução.

A flexibilidade pode ter comprometido em larga escala a qualidade dos cursos de pós-graduação lato sensu. Tanto é assim que a Resolução $n^{\circ} 7 / 2011$, do CNE/CES, no artigo $1^{\circ}$, estabelece a extinção da possibilidade de credenciamento de instituições não educacionais para a oferta de cursos de especialização nas modalidades de educação presencial e a distância. Tal fato representou uma iniciativa de regulação com vistas a preservar uma qualidade mínima nos cursos.

Para a elaboração do novo PNPG 20112020, a Capes instituiu a Comissão Especial de Acompanhamento da Agenda Nacional de Pesquisa, pela Portaria $\mathrm{n}^{\circ} 106$, de 17 de julho de 2012, com o objetivo de acompanhar e monitorar a implantação do PNPG (CAPES, 2013), além de coordenar a elaboração da Agenda Nacional de Pesquisa. A Comissão é composta de representantes de órgãos como: o Ministério da Ciência, Tecnologia e Inovação (MCTI); o Conselho Nacional de Educação (CNE); a Confederação Nacional da Indústria (CNI); a Associação Nacional dos Pós-Graduandos (ANPG); a Universidade Federal de Juiz de Fora (UFJF); o Conselho Nacional de Desenvolvimento Científico e Tecnológico (CNPq); e a Associação Nacional dos Dirigentes das Instituições Federais de Ensino Superior (Andifes), entre outros. 0 relatório apresentado compõe-se, entre outras partes, de recomendações acerca dos temas: avaliação, inovação, internacionalização, redes e associações, interdisciplinaridade e multidisciplinaridade. Pelo que se depreende do relatório, os cursos lato sensu não foram incluídos no PNPG 2011-2020.

Apesar das parcas iniciativas reguladoras do CNE, os cursos continuam se expandindo de forma acelerada e sem acompanhamento e supervisão dos órgãos competentes. Além disso, algumas instituições vêm desconsiderando as normas mínimas para a sua oferta e para a garantia de qualidade. Em face disso, a Secretaria de Regulação e Supervisão da Educação Superior do Ministério da Educação (SERES/MEC) decidiu realizar um novo Cadastro Nacional. A Resolução de 2014 (MEC/CNA/CES, 2014) instituiu o cadastro de oferta de pós-graduação lato sensu (presencial e a distância) para todas as instituições credenciadas no Sistema Federal de Ensino. Entre as principais determinações incluem-se a obrigatoriedade, entre outras, de fornecer dados sobre 
o corpo docente, nome do coordenador, número de vagas e periodicidade dos cursos. A Resolução estabelece, ainda, prazo para cumprimento, pelas instituições de educação superior, das exigências impostas, bem como a sistemática de atualização e coleta futura de dados. Tal iniciativa do MEC tem o objetivo de aferir a dimensão e a qualidade dos cursos de especialização lato sensu para, a partir dessa verificação, propor políticas e regulamentações necessárias para qualificar a oferta desses cursos.

A iniciativa atesta a sua importância em virtude da expansão dos cursos lato sensu voltados para a capacitação de professores de todos os níveis de ensino, notadamente dos níveis fundamental e médio. Tal fato foi comprovado pela recente atuação das autoras do presente texto na coordenação de cursos lato sensu, os quais atraíram significativa parcela de professores, seja pela capacitação em si, seja pela exigência de credenciamento para ascensão na carreira. Confirmase, pois, a necessidade de regulação mais rigorosa por parte do MEC/CNE/CES, especialmente no tocante aos critérios de abertura e oferta dos cursos, particularmente no campo privado. Esta seria uma medida visando a descaracterizar a peculiaridade meramente mercadológica de alguns cursos e a garantir a qualidade dos mesmos.

Por meio da Portaria Normativa $n^{0} 17$, de 28 de dezembro de 2009, a Capes criou o mestrado profissional, com a finalidade de aprimorar a formação técnico-profissional avançada. Diferente dos mestrados tradicionais, a intenção é que os estudantes tenham aulas não só com bons mestres, mas também com profissionais reconhecidos pelo mercado. Verificou-se a necessidade de fortalecer a capacitação e o treinamento de pesquisadores e profissionais para aumentar a capacidade de geração, uso e difusão do conhecimento científico no processo produtivo, inclusive para estimular a criação de novas tecnologias. A intenção, depois da regularização dos mestrados profissionais, é aumentar a oferta desses cursos nos Institutos Federais de Educação, Ciência e Tecnologia. Até meados de 2014, 573 cursos de mestrado profissional já haviam sido autorizados.
A partir da criação desses cursos, a especialização lato sensu começou a perder espaço no sistema de acompanhamento e avaliação da pós-graduação. No entanto, a proliferação dos cursos, notadamente no âmbito privado, deveria merecer a atenção dos órgãos competentes no sentido de garantir a sua qualidade.

Como contribuição ao resgate da pós-graduação lato sensu, algumas considerações serão apresentadas a seguir acerca da importância da gestão pedagógica e institucional desses cursos.

\section{O coordenador de curso como gestor administrativo e pedagógico: em pauta a qualidade dos cursos lato sensu}

Tendo em vista as múltiplas exigências para garantir a qualidade dos cursos de pós-graduação, Franco (2002) elaborou uma proposta para orientar a atuação dos coordenadores, a qual, a seu ver, é a principal referência para o desenvolvimento da gestão pedagógica do projeto acadêmico e para a interlocução entre teoria e prática, entre conteúdos e mercado potencial de trabalho. Para tanto, o autor recomenda que a função primeira do coordenador seja a de gestor pedagógico do curso, que abrange vários requisitos de cunho político, gerencial, pedagógico-acadêmico, político e institucional.

A função do coordenador inclui algumas atribuições que Franco (2002) denomina gerenciais, como a supervisão das instalações físicas e materiais, compreendendo salas de aula, acervo bibliográfico, auditórios, laboratórios e equipamentos, para utilização de alunos e docentes, além da supervisão sistemática da melhor ocupação dos espaços e utilização dos equipamentos e materiais de trabalho, incluindo o uso de sofisticadas tecnologias.

Não obstante o reconhecimento da importância dessas atribuições, as funções acadêmicas destacam-se como o centro das atenções de um coordenador de curso. Sua realização plena depende diretamente do projeto político-pedagógico, entendido como o instrumento definidor do 
papel social da instituição. Centra-se no ensino, mas vincula-se estreitamente aos processos de pesquisa e extensão, tendo como referência o Plano Nacional de Graduação (FÓRUM, 2004). Para atender ao caráter plural e à identidade de cada instituição, o Plano propõe que o projeto pedagógico institucional e dos cursos de graduação e de pós-graduação considere a sua dimensão geral e específica. Para expressar a dimensão global do Projeto Político Pedagógico (PPP), é necessário reconhecer as demandas sociais, econômicas e políticas esperadas da universidade brasileira, advindas da Constituição Federal, da Lei de Diretrizes e Bases da Educação Nacional (LDB) e dos Planos Nacionais de Educação em vigência, bem como dos movimentos sociais e das demandas do mercado.

Em sua dimensão específica, os cursos devem articular-se à vocação institucional, local e/ou regional das instituições de ensino superior (IES) que os oferecem. Entre os requisitos acadêmicos, é desejável que o coordenador: tenha formação de mestrado e/ou doutorado; seja do corpo docente da instituição e esteja inserido nas atividades de ensino e pesquisa. Além disso, é necessária a experiência do coordenador no campo da gestão institucional para fazer com que o curso seja efetivamente desenvolvido em toda a sua capacidade acadêmica.

Franco (2002) apresenta algumas funções requeridas para a atuação do coordenador de curso. A primeira é a função acadêmica, que constitui o núcleo central do curso e que deve ser exercida juntamente com o corpo docente para permitir que, cada vez mais, as atividades pedagógicas tenham de fato um sentido formativo. Para tanto, a seleção docente deve considerar aspectos importantes, que dizem respeito ao estabelecimento de critérios para a indicação de professores, notadamente quanto à sua titulação e qualificação. A função acadêmica supõe, ainda, a construção do projeto pedagógico do curso, a qual não pode prescindir da participação do corpo docente e discente. Portanto, a construção coletiva do projeto incorpora também a função política, visto que não se limita à definição de matrizes curriculares e de conteúdos disciplinares, mas inclui a avaliação do curso nos seus aspectos quantitativo e qualitativo.

Outro fator de qualidade, segundo Franco (2002), é o trânsito externo do coordenador, que inclui o reconhecimento local, regional e nacional ou até mesmo internacional que possui em sua área de conhecimento. Pode ser reconhecido pelos artigos que haja publicado, pelas conferências para as quais seja convidado a proferir, por sua ação no conselho profissional de sua categoria, enfım, pela projeção interna e externa que faz do seu curso. Esta se dá de variadas formas, sendo que algumas podem ocorrer por iniciativa do próprio coordenador. Outras são mais complexas e devem ser definidas no âmbito da instituição, a partir de um planejamento sistemático da própria gestão institucional. Como exemplos, é possível considerar a participação em fóruns acadêmicos, nacionais e internacionais, como seminários, congressos, conferências, ciclos de debates, oficinas e cursos, dentro e fora da instituição. Essa presença que o autor chama de representação externa permite ao coordenador atualizar-se continuamente.

Ainda que tais atividades tenham sua importância na esfera acadêmica, a qualidade dos cursos de pós-graduação exige outras ações dirigidas ao desenvolvimento profissional dos professores cujo suporte mais firme encontra-se na educação continuada. Em sua reflexão sobre o tema, Albuquerque e Gontijo (2010) ressaltam as horas dedicadas às reuniões pedagógicas, nas quais professores e coordenadores realizam um trabalho colaborativo, refletindo sobre situações problemáticas que emergem em sala de aula e traçando estratégias capazes de melhorar a prática docente.

Franco incorpora ainda ao papel do coordenador as funções gerenciais e institucionais. As primeiras implicam a responsabilidade pela supervisão das instalações físicas e materiais, compreendendo salas de aula, bibliotecas, auditórios, laboratórios e equipamentos de informática para utilização de alunos e docentes. Inscreve-se nesse item a indicação de acervo 
bibliográfıco, compreendendo a aquisição de livros, materiais especiais e assinatura de periódicos necessários ao desenvolvimento do curso. A biblioteca de uma instituição educacional pode constituir-se per se em importante centro de atualização bibliográfica, podendo auxiliar o coordenador nas indicações que devam ser feitas para a aquisição de materiais do acervo. Todavia, é da responsabilidade da coordenação solicitar indicações dos professores, selecioná-las nos limites dos recursos disponíveis e cuidar para que ocorram realmente as aquisições pretendidas, assim como as renovações de assinaturas dos periódicos.

As funções institucionais implicam a tarefa de providenciar a aprovação do projeto pedagógico junto aos conselhos de ensino e pesquisa da instituição, que detêm em primeira instância a responsabilidade acadêmica institucional pelo curso. Cabe ao coordenador conhecer as normas institucionais de curso apresentadas pela Capes/MEC e os pareceres do Conselho Nacional de Educação, de modo a propor alterações no projeto pedagógico. Atualmente, a oferta de cursos ainda é regida pela Resolução $n^{\circ} 1$ do CNE/CES de 2007 (BRASIL, 2007), mas é preciso acompanhar o desdobramento da já comentada Resolução de 2014 (MEC/CNA/CES, 2014), que instituiu o cadastro de oferta de pós-graduação lato sensu (presencial e a distância). Ainda que o apelo seja dirigido inicialmente às instituições credenciadas no Sistema Federal de Ensino, é de se supor que o Ministério da Educação e o Conselho Nacional de Educação estejam propensos a acompanhar a oferta de cursos em outras instâncias administrativas e a propor uma política capaz de resgatar a qualidade desse nível de pós-graduação.

Além das propostas aqui apresentadas, as autoras do presente texto entendem que a formação de professores - e também do coordenador - ultrapassa o limite dos cursos iniciais de graduação e a formação em serviço. A educação continuada dos mestres supõe a frequência a cursos de mestrado e doutorado. Esse é o espaço privilegiado para que o processo de capacitação não se limite ao repasse de conhecimentos meramente profissionais, na crença de que isso, por si só, provoque mudanças fundamentais na prática docente. A boa formação se dá em ambiente universitário, lócus da produção do conhecimento, da pesquisa e do diálogo teórico-prático, requisitos determinantes para que os docentes possam refletir sobre aspectos teóricos e rever suas práticas pedagógicas.

\section{Considerações finais}

0 presente texto não tem a intenção de traçar um roteiro pré-determinado para os coordenadores de cursos lato sensu. Cientes da complexidade que permeia a criação e a gestão de cursos de pós-graduação, no setor público ou privado, as autoras apresentam reflexões que podem alimentar um debate profícuo sobre a identidade e a qualidade dos cursos lato sensu.

A relação teoria-prática tem fundamental importância em qualquer curso, sendo de responsabilidade do professor garanti-la. No entanto, o coordenador pode estimular o docente a trazer para o campo prático o conhecimento teórico e a dimensão formativa. Essa é a forma de se garantir a capacidade técnico-científica dos alunos quanto ao compromisso para com a região em que atuarão como profissionais, buscando soluções para os problemas técnicos, econômicos e sociais. A revolução no campo da tecnologia e do conhecimento não pode ser considerada um valor per se, visto que se funde com as questões estruturais de cada país. Forma com estas um sistema complexo, em que se entrelaçam as relações de produção, a ação social e a política educacional e de emprego. Desse modo, a qualidade de um curso lato sensu deixa de ser limitada aos reclamos do mercado e passa a ser referenciada, também, pela sua função social.

Esse enfoque permite, pois, que o curso enseje a compreensão da dinâmica que rege as práticas sociais nas quais o indivíduo constrói sua identidade, inclusive como estudante e trabalhador. Não se trata de estabelecer um hiato entre conhecimento para o trabalho e conhecimento crítico. 0 processo educacional, ainda que seja voltado para a preparação para 
o trabalho, pode esclarecer quais os fatores que determinarão o acesso (ou a exclusão) dos indivíduos a uma educação de qualidade e a melhores oportunidades no mundo laboral. Com essa compreensão, o ato educativo responde ao apelo de Adorno (1995) para que a educação, seja de cunho geral ou profissionalizante, tenha o sentido emancipador de fazer o indivíduo senhor de seu próprio entendimento sobre o mundo e, portanto, senhor de si mesmo no âmago do mercado competitivo.

Depreende-se, pois, que os novos projetos e/ou estratégias inovadoras no campo educacional não podem deixar de considerar a tensão que se produz no âmbito do ensinar, pesquisar e aprender nas instituições de educação superior. De um lado, a prática pedagógica conservadora, sustentando os campos científicos para o exercício profissional; de outro, a certeza de que o processo ensino-aprendizagem deve empenhar-se na sua própria reconstrução, de forma a acompanhar as transformações e as demandas do novo espaço sociocultural, que ultrapassam o limite de um exercício profıssional imediato. A instituição e o coordenador de curso certamente sofrerão as injunções próprias da gestão institucional - em seus aspectos ideológicos, administrativos e financeiros -, que podem facilitar ou criar óbices ao desempenho de suas funções. Não obstante, pertence a ele, coordenador, a prerrogativa de dar sentido e concretude às atividades-fım. Como incentivador do processo coletivo de construção do projeto pedagógico, tem que se abrir aos contrastantes pontos de vista, que incluem todos os protagonistas da ação educativa: diretores institucionais, servidores, professores, estudantes. A condução participativa é a forma de superar a visão de uma pedagogia restrita ao desenvolvimento instrumental do fazer pedagógico e à administração centrada em atividades-meio.

Por todas essas exigências, a função do coordenador é, ao mesmo tempo, política e pedagógica. De acordo com Fonseca, em artigo anterior (2004), a qualidade do curso demanda: o domínio de conhecimentos referentes aos processos institucionais que compreendem a gestão física e financeira; a utilização das tecnologias de informação e de comunicação; a organização do trabalho pedagógico; a avaliação do processo ensino-aprendizagem; e a avaliação institucional, em sua dimensão interna (autoavaliação). Os requerimentos que lhe são impostos, especialmente na função tridimensional de professor, pesquisador e gestor, exigem a constante renovação de conhecimentos nos campos teórico, epistemológico e técnico-científico.

0 Fórum de Pró-Reitores de Graduação das Universidades Brasileiras (2007) destacou que a universidade começou a perceber a importância da autonomia para apresentar soluções próprias para os problemas da educação superior e não reproduzir fórmulas predeterminadas. Essas soluções passam necessariamente pela atitude de experimentar novas opções de cursos e alternativas didáticas e pedagógicas. 0 fórum fez considerações sobre a pós-graduação lato sensu nos diferentes aspectos do fazer acadêmico: os métodos e as estruturas administrativas, os recursos humanos disponíveis e a infraestrutura física necessária à qualidade das atividades acadêmicas. 0 projeto político pedagógico é referido como meio para se definir as prioridades para a gestão de cursos em sua dimensão interna e externa. 0 grande desafio, segundo o fórum, é motivar a elaboração de um projeto próprio, dinâmico e construído coletivamente em cada IES e que englobe, mas não fique restrito, à elaboração de um Plano de Desenvolvimento Institucional (PDI), o qual atende prioritariamente às atividades de credenciamento e recredenciamento de cursos e instituições.

Há que considerar, pois, que os cursos de especialização lato sensu, pela sua importância formativa no campo técnico-profissional e na educação continuada, vêm sendo desafiados pela reconfiguração metodológica da ciência e das diferentes funções atribuídas ao conhecimento, considerando a sua articulação direta com o mercado e/ou com o desenvolvimento social.

No esforço de qualificar a oferta dos cursos, a avaliação emerge como ferramenta construtiva para identificar possibilidades, orientar, justificar, escolher e tomar decisões quanto ao perfil desejado do curso e quanto à 
sua pertinência para a inserção dos alunos na dinâmica social. Esse quesito demanda, ainda, um processo permanente de acompanhamento dos egressos por parte da instituição, como estratégia para aperfeiçoar a qualidade do ensino.

Aos gestores institucionais cabe fazer escolhas, as quais certamente podem direcionar o projeto educativo para acatar as expectativas - e até mesmo cobranças - do mercado de trabalho ou para garantir a condição cidadã do indivíduo como ator social. No sentido que lhe dá Adorno (1995), as duas dimensões não são excludentes. No campo educacional, significa aparelhá-lo de conhecimentos que não se limitem à atuação eficiente da prática profissional, mas que possam dotá-lo de autonomia para compreender e fazer frente aos interesses econômicos e ideológicos que permeiam o meio profissional e a dinâmica social em todas as suas manifestações.

Ao Ministério da Educação e ao Conselho Nacional de Educação cabe zelar por uma re- gulação que seja efetiva na garantia dos critérios de qualidade do ensino. Considerando que a Resolução n 1, de 2007 (BRASIL/CNE, 2007), foi elaborada ainda em um contexto de desregulação da oferta dos cursos lato sensu, seria oportuna uma reavaliação da oferta dos cursos por parte do MEC/CNE. A Resolução de 2014 (MEC/CNA/CES, 2014) já estabeleceu critérios para o acompanhamento de cursos por meio de levantamento de dados em todas as instituições credenciadas no Sistema Federal de Ensino. A iniciativa, se levada a cabo em seu esforço de regulação e supervisão, pode significar um avanço para a qualidade dos cursos de pós-graduação lato sensu. Tal iniciativa ganha força pelo fato de que esses cursos vêm sendo procurados por professores de nível básico e superior, seja para melhorar a sua capacitação docente seja para adquirir credenciais em prol do avanço na carreira. Em qualquer dos casos, a melhoria do padrão desses cursos para a formação docente torna-se conduto para a qualidade da educação brasileira.

\section{Referências}

ADORNO, Theodor W. Educação e emancipação. São Paulo: Paz e Terra, 1995.

ALBUQUERQUE, Leila C.; GONTIJO, Cleyton H. coordenação pedagógica com cenário de formação e desenvolvimento profissional docente. In: CUNHA, Celio da; SOUSA, José Vieira; SILVA, Maria Abadia (Org.). Diversidade metodológica na pesquisa em educação. Campinas: Autores Associados, 2013. p. 165-2010.

BRASIL. Decreto n. 29.741, de 11 de julho de 1951. Coleção de Leis do Brasil, Brasília, DF, v. 6, p. 8, 1951. Disponível em: <http://www2.camara. leg.br/legin/fed/decret/1950-1959/decreto-29741-11-julho-1951-336144-norma-pe.html>. Acesso em: 12 abr. 2013.

BRASIL. Lei n. 9.394, de 20 de dezembro de 1996, estabelece diretrizes e bases da educação nacional. Diário Oficial da União, Brasília, DF, 23 dez. p. 27.833-27.841, 1996.

BRASIL. Portaria Normativa n. 17, de 28 de dezembro de 2009. Diário Oficial da União, Brasília, DF, n 248, 29 dez. 2009. Seção 1, p. 20. Disponível em: <www.ipt.br/download.php?filename=444-Portaria_Normativa_n_17.pdf >. Acesso em: 12 abr. 2013.

BRASIL. Resolucão CNE/CES n. 03, de 1999 - fixa condições de validade dos certificados de cursos presenciais especialização. Diário Oficial da União, Brasília, DF, 7 out. 1999. Seção 1, p. 52. Disponível em: <portal.mec.gov.br/cne/arquivos/pdf/rces03_99.pdf>. Acesso em: 12 abr. 2013.

BRASIL. Capes. SNPG 2014. Brasília, DF, Capes, Disponivel em: <http://www.capes.gov.br/avaliacao/dados-do-snpg>. Acesso em: 12 abr. 2013. BRASIL. Ministério da Administração Federal e Reforma do Estado. Plano Diretor da Reforma do Estado. Brasília, DF: MARE, 1995.

BRASIL. Ministério da Educação. Censo da educação superior: dados de 2009 e 2012. Brasília, DF: MEC, [200-].

BRASIL. Ministério da Educação. Parecer CNE/CES n. 213, de 2004: estabelece parâmetros que distinguem as modalidades de pós-graduação lato sensu, denominadas "especialização" e "aperfeiçoamento". Brasília, DF: MEC, [2004]. Disponível em: <portal.mec.gov.br/cne/arquivos/pdf/ pces213_04.pdf>. Acesso em: 12 abr. 2013.

BRASIL. Ministério da Educação. Portaria nº 1.180, de 06 de maio de 2004. Diário Oficial da União, Brasília, DF, n. 87, seção 2, 7 maio 2004.

BRASIL. Ministério da Educação. Resolução CNE/CES, n. 01, de 08 de junho de 2007: estabelece normas para o funcionamento de cursos de pós-graduação lato sensu em nível de especialização. Brasília, DF: MEC, [2007]. Disponível em:<portal.mec.gov.br/cne/arquivos/pdf/rces001_07. pdf >. Acesso em: 12 abr. 2013. 
BRASIL. Ministério da Educação. Resolução CNE/CES, n. 07, de 2011: determina a suspensão da tramitação dos processos que visavam ao credenciamento especial de instituições não educacionais para a oferta de cursos de especialização. Brasilia, DF: MEC, [2011]. Disponível em: <portal.mec.gov.br/index.php?option=com_docman\&task>. Acesso em: 12 abr. 2013.

BRASIL. Ministério da Educação. Resolução do MEC/CNE/CES, nº 2, de 12 de fevereiro de 2014: institui o cadastro de oferta de pós-graduação lato sensu (especialização das instituições credenciadas no Sistema Federal de Ensino). Brasília, DF: MEC, [2014]. Disponível em: <www.sead. ufba.br/.../resolucao_cne_ces_02_2014_cadastro_nacional_de... >. Acesso em: 12 abr. 2013.

BRASIL. Ministério da Educação/Capes. Critérios para implantação de mestrado e doutorado. Brasília, DF: Capes, 2005.

BRASIL. Ministério da Educação/Capes. Plano Nacional de Pós-Graduação (PNPG) 2005-2010. Brasília, DF: MEC/Capes, 2005.

BRASIL. Ministério da Educação/Capes. Relatório da Comissão de Acompanhamento do PNPG 2011-2020. Brasília, DF: Coordenação de Comunicação Social da Capes, 2013.

BRASIL. Ministério da Educação/Capes. Conselho Nacional de Educação. Resolução CNE/CES, n. 01, de 2001. Autorização e credenciamento dos cursos de pós-graduação stricto sensu; Funcionamento dos cursos de pós-graduação lato sensu. Diário Oficial da União, Brasília, DF, 3 abr. 2001. Seção 1. Disponível em: <portal.mec.gov.br/seed/arquivos/pdf/tvescola/leis/CES0101.pdf>. Acesso em: 12 abr. 2013.

BRASIL. Ministério da Educação. Conselho Federal de Educação. Parecer n. 977, de 1965. Brasília, DF: MEC, [200-].

BRASIL. Ministério do Planejamento, Orçamento e Gestão. 0 desafio do planejamento governamental. Brasília, DF: MP. Secretaria de Planejamento e Investimentos Estratégicos, 2002.

COSTA, Paulo A. Lima. Educação Superior na Câmara dos Deputados: um estudo sobre a pós-graduação lato sensu. 2010. 186 f. Dissertação (Mestrado em Educação) - Universidade de Brasília, Brasília, DF, 2010.

FONSECA, Dirce. Contribuições ao debate da pós-graduação lato sensu. Revista Brasileira de Pós-Graduação, Brasília, DF, v. 1, n. 2, p. 173182, nov. 2004.

FÓRUM DE PRÓ-REITORES DE GRADUAÇÃO DAS UNIVERSIDADES BRASILEIRAS (FORGRAD). Plano Nacional de Graduação: um projeto em construção. Curitiba: Forgrad, 2004. Disponível em: <http://www.forgrad.org.br/pages/publicacoes.htm>. Acesso em: mar. 2007.

FRANCO, Édson. Funções do coordenador de curso: como construir o coordenador ideal. Brasília, DF: Abmes, 2002.

HARVEY, David. Condição pós-moderna. São Paulo: Loyola, 1992.

MORAES, Valéria $S$ de. As políticas públicas educacionais para a pós-graduação lato sensu no Brasil: tendências atuais. In: ENCONTRO INTERNACIONAL DE EDUCAÇÃ̃O COMPARADA, 5., Belém. Encontro... Belém: SBEC, 2010.

NUNES, Marcos A. Agências executivas: estratégias de reforma administrativa. Brasília, DF: MARE/ENAP, 1998.

OLIVEIRA, João F.; FONSECA, Marília. A educação em tempos de mudança: reforma do estado e educação gerenciada. Revista Impulso, Piracicaba, v. 16, n. 40, p. 55-66, 2005.

PILATTI, Orlando. Especialização: falácia ou conhecimento aprofundado? Revista Brasileira de Pós-graduação. Brasília, v. 3, n. 5, jun. 2006.

SILVA, Vanderlúcia G. Pós-graduação latu sensu: um estudo da gestão dos cursos ofertados pelas universidades do Distrito Federal. 2008. 184 f. Dissertação (Mestrado) - Universidade de Brasília, Brasília, DF, 2008

SOUZA, Paulo Renato. Avaliação e expansão do ensino superior. Folha de S. Paulo, Tendências/Debates, 21 dez. 1999.

Recebido em: 13.06.2014

Aprovado em: 21.10 .2014

Marília Fonseca é professora colaboradora e pesquisadora sênior do Programa de Pós-Graduação da Faculdade de Educação da Universidade de Brasília (UnB). É professora do Programa de Pós-Graduação em Educação da Universidade Federal da Grande Dourados (UFGD) e bolsista de Desenvolvimento Regional (DCR) da Fundação de Apoio ao Desenvolvimento do Ensino, Ciência e Tecnologia do Estado de Mato Grosso do Sul (FUNDECT/CNPq).

Dirce Mendes da Fonseca é mestre em educação pela Universidade Estatual de Campinas (UNICAMP). Doutora em sociologia pela Universidade de Brasília (UnB), onde atuou como professora adjunta no Programa de Pós-Graduação da Faculdade de Educação e participou de pesquisas na área de gestão e política da educação. É membro do Núcleo de Esstudos da Infância e Juventude do Centro de Estudos Avançados Multidisciplinares (CEAM) da UnB. É membro do Conselho Superior da Fundação de Apoio à Pesquisa do Distrito Federal (FAP/DF). 